\title{
Honokiol combined with curcumin sensitizes multidrug-resistant human lung adenocarcinoma A549/DDP cells to cisplatin
}

\author{
MINGMING QI $^{1}$, XIAOJIN CHEN $^{2}$, LIQUN BIAN $^{3}$, HAN ZHANG $^{1}$ and JIAN MA ${ }^{1}$ \\ ${ }^{1}$ Department of Febrile Diseases, School of Chinese Medicine, ${ }^{2}$ Hanlin College, \\ Nanjing University of Chinese Medicine, Nanjing, Jiangsu 210023; ${ }^{3}$ Digestive Department, \\ Xiyuan Hospital, China Academy of Chinese Medicine Sciences, Beijing 100091, P.R. China
}

Received May 30, 2019; Accepted March 20, 2020

DOI: $10.3892 / \mathrm{etm} .2021 .10736$

\begin{abstract}
The aim of the present study was to discuss the effects and underlying mechanisms of honokiol (HNK) and/or curcumin (CUR) in sensitization of multidrug-resistant human lung adenocarcinoma A549/DDP cells to cisplatin (DDP). An MTS assay was performed to detect the cytotoxicity of HNK, CUR and DDP in A549 and A549/DDP cells and compare their sensitivity. The A549/DDP cells were then divided into 8 groups: Control, HNK, CUR, DDP, HNK + CUR, HNK + DDP, CUR + DDP and HNK + CUR + DDP. Cell proliferation was measured by MTS assay and colony formation assay, cell apoptosis was detected by flow cytometry, cell invasion was evaluated by Transwell assay and cell migration was determined by a wound healing assay. In order to investigate the possible mechanisms, P-glycoprotein (P-gp) protein expression was measured by western blotting and immunofluorescence assays. The mRNA expression levels of AKT, Erk1/2, cyclin-dependent kinase inhibitor 1 (P21), caspase 3, cleaved caspase 3, caspase 9, cleaved caspase 9, poly (ADP-ribose) polymerase (PARP), cleaved PARP, matrix metalloproteinase (MMP)-2 and MMP-9 were examined by reverse transcription-quantitative (RT-q) PCR assay, and the protein expression levels of phosphorylated (p)-AKT, p-Erk1/2, P21, caspase 3, cleaved caspase 3 , caspase 9 , cleaved caspase 9 , PARP, cleaved PARP, MMP-2 and MMP-9 proteins expression by western blot assay. The MTS assay demonstrated that HNK $(5 \mu \mathrm{g} / \mathrm{ml})$, CUR $(10 \mu \mathrm{g} / \mathrm{ml})$ and DDP $(5 \mu \mathrm{g} / \mathrm{ml})$ had no obvious toxicity to A549/DDP cells, and HNK, CUR and DDP were more sensitive in A549 cells compared with A549/DDP cells. The optimal concentrations of HNK $(5 \mu \mathrm{g} / \mathrm{ml})$, CUR $(10 \mu \mathrm{g} / \mathrm{ml})$ and DDP $(5 \mu \mathrm{g} / \mathrm{ml})$ were chosen to carry out the further experiments. Compared with the control group, no significant
\end{abstract}

Correspondence to: Dr Jian Ma, Department of Febrile Diseases, School of Chinese Medicine, Nanjing University of Chinese Medicine, 138 Xianlin Road, Nanjing, Jiangsu 210023, P.R. China E-mail: 13770688811@163.com

Key words: honokiol, curcumin, resistance, A549/DDP cells, P-glycoprotein change was observed in cell proliferation, apoptosis, migration, invasion and related mRNA and protein expression in HNK, CUR, DDP and HNK + CUR groups. The cell proliferation rate in the HNK + DDP and CUR + DDP groups was significantly suppressed with cell apoptosis significantly increased, respectively. The invasion cell number and wound healing rate of HNK + DDP and CUR + DDP groups were significantly depressed compared with the control group, respectively. Immunofluorescence demonstrated that the nuclear volume of P-gp in HNK + DDP and CUR + DDP groups were significantly downregulated compared with the control group, respectively. The RT-qPCR assay demonstrated that the AKT, Erk1/2 and P21 mRNA expression levels were significantly decreased and cleaved caspase 3, cleaved caspase 9 and cleaved PARP were increased in HNK + DDP and CUR + DDP groups compared with the control group. The western blotting results were consistent with the RT-qPCR results. NK + CUR + DDP had improved effects on A549/DDP compared with HNK + DDP or CUR + DDP group, respectively. HNK and/or CUR could improve the sensitivity of DDP to A549/DDP cell by the regulation of P-gp, inducing apoptosis, and inhibiting migration and invasion via AKT/ERK signal pathway in an in vitro study.

\section{Introduction}

The incidence of lung cancer in China is increasing at $\sim 1.63 \%$ per year (1) and the total number of patients with lung cancer is expected to reach 1 million, which would be the largest population of lung cancer patients in the world (2-4). Although new therapeutic techniques for lung cancer are continuously being developed, the 5-year survival for patients with non-small cell lung cancer (NSCLC) remains below $15 \%$ (5). Platinum-based chemotherapy is the first-line treatment for advanced NSCLC patients with no or unknown driver mutations and programmed death-ligand $1<1 \%$ or unknown, but unfortunately, $70-80 \%$ of the patients are resistant to it (6).

Cisplatin (DDP) enters cancer cells by cell surface transporters, such as high affinity copper uptake protein 1 and they form positively charged molecules that bind to DNA to form cross-linked adducts, which inhibit transcription and replication and induce apoptosis of the cancer cells (6). Studies have shown that resistance to DDP in NSCLC cells was mainly represented by deletion of the DDP transporter or reduced 
activity of metallothionein and glutathione-related metabolic enzymes (such as glutathione), which convert DDP into positively charged compounds, which loses its ability to inhibit DNA repair (7). Several targeted drugs aiming at this pathway have been developed in previous years, for example picoplatin, which was expected to increase the activity of glutathione (8). However, the efficacy of these drugs for DDP-resistant tumors remained poor and none of them can effectively reverse DDP resistance in NSCLCs.

Honokiol (HNK), mainly derived from the traditional Chinese medicine Magnolia, is a representative of the biphenyl lignans (9). It has various pharmacological effects, including anti-infection, anti-anxiety and anti-oxidation, and previous studies have shown that HNK may regulate signaling pathways involved in stemness maintenance of tumor stem cells, such as the Notch signaling pathway (10-13).

Curcumin (CUR) is an acidic polyphenolic substance and is a diketone compound, widely found in the root and stem of various plants such as turmeric, medlar and calamus. CUR has a wide range of pharmacological effects, such as anticoagulation, hypolipidemic effects, anti-oxidation, anti-inflammatory, anti-atherosclerosis, antitumor and antirheumatic effects, and liver, biliary and stomach-protecting effects. CUR shows very limited toxic side effects. Therefore, its anticancer effect has attracted increasing attention and the National Cancer Institute of USA has listed it as one of the third-generation cancer chemopreventive drugs (14).

$\mathrm{P}$-glycoprotein (P-gp) is a high molecular weight glycoprotein encoded by the multidrug resistance (MDR)1 gene and belongs to the classical ATP-binding cassette transporter family. Overexpression of P-gp is one of the most important causes of MDR.P-gp has been shown to regulate the AKT/ERK signaling pathway $(15,16)$. Caspase- 3 , caspase- 9 and poly(ADP ribose) polymerase (PARP) are the key proteases about cell apoptosis. P21 is a cyclin-dependent kinase inhibitor to regulate cancer progression (17). Matrix metalloproteinases (MMPs) are a big family of proteinases that are involved in numerous pathophysiological processes (18). Thus far, the role and possible mechanisms of HNK combined with CUR on resistance of lung cancer cells to DDP has not been elucidated. The present study investigated the effects of HNK combined with CUR to reverse drug resistance of A549/DDP cell lines and explored the underlying mechanisms in vitro experiments.

\section{Materials and methods}

Reagents and instruments. Human lung cancer A549 and A549/DDP cell lines were provided by ATCC. A549 cell culture medium RPMI-1640 and A549/DDP cell culture specific medium (RPMI-1640 + 10\% FBS + 1-2 $\mu \mathrm{g} / \mathrm{ml} \mathrm{DDP}+1 \%$ penicillin/streptomycin) were purchased from Gibco(ThermoFisher Scientific, Inc.). HNK, CUR and DDP were purchased from Sigma-Aldrich (Merck KGaA). Transwell chambers were purchased from BD Biosciences; Becton, Dickinson and Company. Non-radioactive cell proliferation assay (MTS) reagent and reverse transcription-quantitative (RT-q) PCR kit were purchased from Promega Corporation. The Apoptosis assay kit was purchased from BD Biosciences; Becton, Dickinson and Company. The specific primary antibodies against p-gp (cat.no. ab262880), p21 (cat.no. ab80633;), MMP-2 (cat. no. ab2462), MMP-9 (cat. no. ab119906), phosphorylated (p)-AKT (cat. no. ab38449), p-Erk1/2 (cat. no. ab214362), AKT (cat. no. ab18785), ERK (cat. no. ab109282), Cleaved-caspase-3 (cat.no.ab2302), Caspase-3 (cat.no.ab4051), Cleaved-caspase-9 (cat. no. ab2324), Caspase-9 (cat. no. ab52298), Cleaved-PARP (cat. no. ab32561), PARP (cat. no. ab74290) and GAPDH (cat. no. ab181602). All of these antibodies were purchased from Abcam. ECL immunoblot substrate was purchased from EMD Millipore. Flow cytometry was performed with a BD FACSCalibur ${ }^{\mathrm{TM}}$ machine (BD Biosciences; Becton, Dickinson and Company). Microplate reader and PCR instrument were from Thermo Fisher Scientific, Inc.

Cell culture and grouping. A549 and A549/DDP cells (1x10 $\left.{ }^{3}\right)$ were cultured in a $10 \mathrm{~cm}$ culture dish in a $37^{\circ} \mathrm{C}, 5 \% \mathrm{CO}_{2}$ and humidified incubator with $90 \%$ Eagle's minimum essential medium (EMEM; Gibco; Thermo Fisher Scientific, Inc.) supplemented with $10 \%$ fetal bovine serum (FBS; Gibco; Thermo Fisher Scientific, Inc.). Cells were digested with $0.25 \%$ trypsin-EDTA for passage. The cells were divided into 8 groups: Control group of normally cultured A549/DDP cells, HNK group treated with $5 \mu \mathrm{g} / \mathrm{ml}$ of HNK, CUR group treated with $10 \mu \mathrm{g} / \mathrm{ml}$ of CUR, DDP group treated with $5 \mu \mathrm{g} / \mathrm{ml} \mathrm{DDP}$ and HNK + CUR, HNK + DDP, CUR + DDP and $\mathrm{HNK}+\mathrm{CUR}+\mathrm{DDP}$ groups that received combinations of drugs implied by the group names at the same doses as the single drug groups.

MTS assay. Each group of A549/DDP cells was cultured and treated as described above for 24,48 and $72 \mathrm{~h}$, then the medium was aspirated, MTS reagent was added according to the manufacture's protocol, then optical density value was measured at $490 \mathrm{~nm}$ by a microplate reader and the proliferation rate of each group of A549/DDP cells was calculated.

Colony formation assay. The proliferation of cells was detected by colony formation assay. Briefly, cells (200 cells/well) were cultured in 6-well plates for $12 \mathrm{~h}$ and then treated with the drugs as described above and incubated for two weeks. Cells were immobilized for $15 \mathrm{~min}$ with $95 \%$ methanol at room temperature and then stained with hematoxylin at room temperature for $1 \mathrm{~min}$. The clones were stained by $0.1 \%$ crystal violet at room temperature and were counted by light microscopy (magnification, $\mathrm{x} 40$ ). The clone formation rate was calculated by using $>50$ cell colonies as one clone (Clone formation rate $=$ number of clones/number of inoculated cells $\times 100 \%)$.

Flow cytometry for apoptosis. Each group of A549/DDP cells $\left(3 \times 10^{4}\right)$ was treated as described above for $48 \mathrm{~h}$ before $20 \mu \mathrm{l}$ of PI and $20 \mu \mathrm{l}$ of Annexin V-FITC (BD Biosciences) were added to each group and incubated for $15 \mathrm{~min}$, the cells were then collected and adjusted to $1 \times 10^{4} / \mathrm{ml}$ for flow cytometry to determine apoptosis of each group. Cell apoptosis was assessed using flow cytometry (FACScan ${ }^{\mathrm{TM}}$; BD Biosciences) and analyzed using FlowJo 10.06 software (FlowJo LLC).

Wound healing assay for migration. After counting, the cells were seeded to 6 -well plate at $5 \times 10^{6}$ cells/well and cultured with $10 \%$ serum at $37^{\circ} \mathrm{C}$. When the cells reached confluence, a straight line was scratched using a $200 \mu \mathrm{l}$ tip on the cell 
monolayer and the width of the scratch was recorded under a microscope. The cells were washed 3 times with PBS, serum-free medium added and then treated as described above for 0,24 or $48 \mathrm{~h}$. Cells were observed and images were captured under a light microscope (magnification, x200; Olympus Corporation). A total of three parallel wells were used for each group and the experiment was carried out in triplicate.

Transwell assay for invasion. Matrigel was diluted with serum-free EMEM at 1:3 and 35-45 $\mu \mathrm{l}$ of the solution was added to the Transwell chambers and incubated at $37^{\circ} \mathrm{C}$ for 4-5 h. Cell density was adjusted to $1 \times 10^{5} / \mathrm{ml}$ with medium containing $5 \%$ FBS. Then, $0.2 \mathrm{ml}$ of the cell suspension was added the upper Transwell chambers of each group and treated accordingly. Afterwards, $350 \mu \mathrm{l}$ EMEM containing $20 \% \mathrm{FBS}$ was added to the lower chambers and cultured at $37^{\circ} \mathrm{C}$, $5 \% \mathrm{CO}_{2}$ for $48 \mathrm{~h}$. Cells on the upper surface of the chamber was wiped off and the culture solution in the lower chamber was replaced with $350 \mu 10.5 \%$ Wright-Giemsa dye solution so that the dye solution was just in contact with the lower surface of the chamber. The lower surface of the chamber was brought into contact with the surface of the dye solution and stained at room temperature for $5 \mathrm{~min}$. Then $175 \mu \mathrm{l}$ of the dye was removed and $175 \mu \mathrm{l}$ of $\mathrm{dd}_{2} \mathrm{O}$ was added. After 10 min of incubation, 4 fields of view were imaged under a light microscope (magnification, $\mathrm{x} 400$ ) and the number of invading cells counted using ImageJ software V1.8.0.112 (National Institutes of Health).

RT-qPCR assay. A549/DDP cells $\left(1 \times 10^{5}\right)$ in logarithmic growth phase were treated for $48 \mathrm{~h}$ and total RNA was extracted by TRIzol ${ }^{\circledR}$ reagent (Invitrogen; Thermo Fisher Scientific, Inc.) according to the manufacturer's protocol. The cDNA was reverse transcribed by SuperScript ${ }^{\mathrm{TM}}$ IV CellsDirect ${ }^{\mathrm{TM}}$ cDNA Synthesis Kit (Thermo Fisher Scientific, Inc.) according the following temperature protocol: $42^{\circ} \mathrm{C}$ for $60 \mathrm{~min}, 70^{\circ} \mathrm{C}$ for $15 \mathrm{~min}$ and chilling at $4^{\circ} \mathrm{C}$. qPCR was performed using a SYBR ${ }^{\circledR}$ Premix Ex Taq ${ }^{\mathrm{TM}}$ (cat. no. DRR041A, Takara Bio, Inc.) on an Applied Biosystems thermal cycler (Applied Biosystems; Thermo Fisher Scientific, Inc.) according to the manufacturer's protocol: The parameters for qPCR assays were denaturation at $94^{\circ} \mathrm{C}$ for $3 \mathrm{~min} ; 40$ cycles of $95^{\circ} \mathrm{C}$ for $5 \mathrm{sec}, 65^{\circ} \mathrm{C}$ for $35 \mathrm{sec}$ and $72^{\circ} \mathrm{C}$ for $60 \mathrm{sec}$; and finally, $72^{\circ} \mathrm{C}$ for $5 \mathrm{~min}$. Fold changes were calculated using the $2^{-\Delta \Delta \mathrm{Cq}}$ method (19). Primer sequences used were as follows: AKT forward, 5'-GGACAACCGCCATCCAGACT-3' and reverse, 5'-GCCAGGGACACCTCCATCTC-3', Erk1/2 forward, 5'-CTAAACCACATCGGGAACCT-3' and reverse, 5'-TAC TTCCGGGCTTTGATGGA-3'; P21 forward, 5'-CAGAGC CACAGGCACCAT-3' and reverse, 5'-GCGAAGTCAAAG TTCCACC-3'; Caspase 3 forward, 5'-ATGGAGAACAAT AAAACCT-3' and reverse, 5'-CTAGTGATAAAAGTAGAG TTC-3'; PARP forward, 5'-GGCATCGGAACTGGACGA GG-3' and reverse, 5'-CCCCACGAACGGAACAACCA-3'. P-gp forward, 5'-CGCAGGCAGGTGATAAGGGG-3' and reverse, 5'-GCAATGCGGTCTGCGTTCTG-3'. MMP-2 forward, 5'-CAGGACATTGTCTTTGATGGCATCGC-3' and reverse, 5'-CAGGACATTGTCTTTGATGGCATCGC-3'; MMP-9 forward, 5'-CAGGACATTGTCTTTGATGGCATC GC-3' and reverse, 5'-CAGGACATTGTCTTTGATGGCATC
GC-3' and GAPDH forward, 5'-GGACCTGACCTGCCGTCT AG-3' and reverse, 5'-GTAGCCCAGGATGCCCTTGA-3'. GAPDH was used as an internal standard.

Immunofluorescence. The cells were permeabilized for $30 \mathrm{~min}$ in $0.5 \%$ Triton $\mathrm{X}-100$ and incubated for $1 \mathrm{~h}$ at room temperature with a primary antibody diluted in PBS supplemented with $3 \%$ bovine serum albumin (Beyotime Institute of Biotechnology). The cells were rinsed with PBS and incubated with $2 \mu \mathrm{g} / \mathrm{ml}$ Alexa Fluor ${ }^{\circledR} 488$-conjugated goat anti-rabbit IgG antibody (secondary antibody; ab150085; 1:5,000) for $2 \mathrm{~h}$ at room temperature. Nuclei were counterstained with DAPI with 5 min incubation at room temperature. After washing with PBS, the slides were mounted in the Vectashield mounting medium and examined under a FluoView FV1000 confocal microscope (Olympus Corporation) and analyzed with the Olympus FluoView ver. 1.7b viewer (Olympus Corporation).

Western blotting for protein levels of P-gp, $p$-AKT, $p$-Erk1/2, P21, MMP-2, MMP-9 and apoptosis related proteins. Each group of A549/DDP cells in the logarithmic growth phase was treated with the corresponding treatment for $48 \mathrm{~h}$ and lysed using cell lysis buffer (Beyotime Institute of Biotechnology) to extract total protein. Protein concentrations of the lysate were measured by the Bicinchoninic acid Protein Assay kit (Beyotime Institute of Biotechnology) and equal amounts $(5 \mu \mathrm{g})$ of the protein loaded on a 12\% SDS-PAGE for electrophoresis separation. The protein bands were then transferred to PVDF membrane. The membranes were then blocked with $5 \%$ non-fat milk in TBS- $0.1 \%$ Tween buffer at room temperature, following which they were incubated with specific primary antibodies at $4{ }^{\circ} \mathrm{C}$ overnight, washed, incubated with horseradish peroxidase-conjugated secondary antibody (cat. no. ab97040; 1:1,000; Abcam) at room temperature for $1 \mathrm{~h}$, washed again and developed with enhanced chemiluminescence (EMD Millipore). GAPDH was used as the internal reference. ImageJ software (ver. 1.48, National Institutes of Health) was used for quantification of the band intensity. The dilutions used for each of the specific primary antibodies were as follows: P-gp (1:1,000), p21 (1:1,000), MMP-2 (1:1,000), MMP-9 (1:1,000), p-AKT (1:1,000), p-Erk1/2 (1:1,000), AKT (1:1,000), ERK (1:1,000), Cleaved-caspase-3 (1:1,000), Caspase-3 (cat. no. ab4051; 1:1,000), Cleaved-caspase-9 $(1: 1,000)$, Caspase-9 $(1: 1,000)$, Cleaved-PARP $(1: 1,000)$, PARP $(1: 1,000)$ and GAPDH $(1: 1,000)$.

Statistical analysis. All assays were repeated at least three times and statistical analysis was performed using SPSS ver. 19.0 (IBM Corp.) statistical software. Measurement data was expressed as mean \pm standard deviation and the difference between the groups was compared by one-way analysis of variance followed by Tukey's post hoc test. $\mathrm{P}<0.05$ was considered to indicate a statistically significant difference.

\section{Results}

Effects of HNK, CUR and DDP on A549/DDP cell viability. The MTS assay was performed to assess the effect of HNK, CUR and DDP on the viability of A549 and A549/DDP cells, 
A

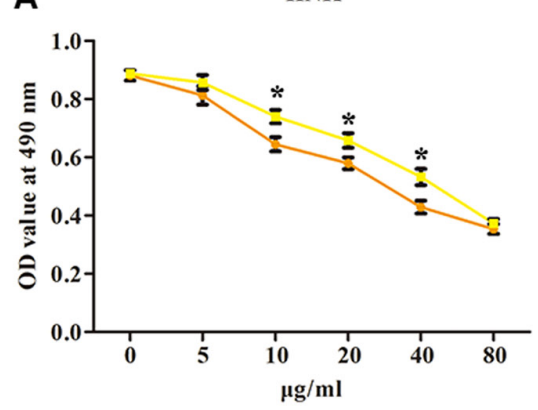

C

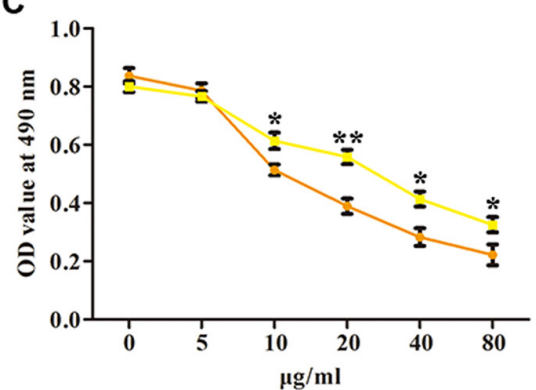

B

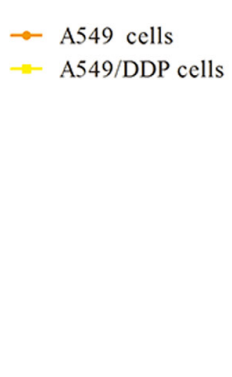

$\rightarrow$ A549 cells

- A549/DDP cells
CUR

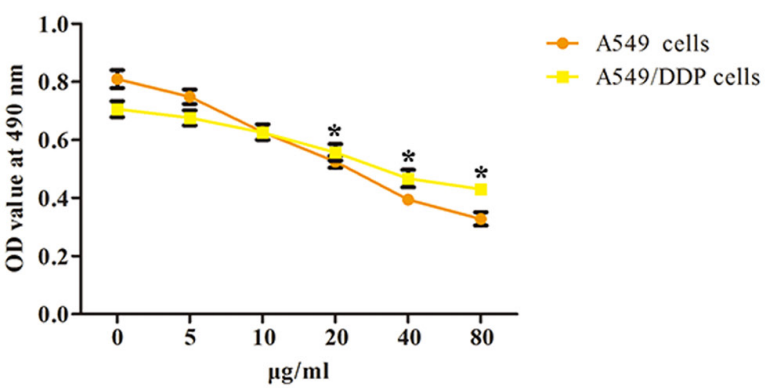

Figure 1. Effect of HNK, CUR and DDP on the A549 and A549/DDP cells viability. The viabilities of A549 and A549/DDP cells treated with (A) HNK, (B) CUR and (C) DDP were assessed by MTS assay. The results were expressed as the mean \pm standard deviation of three independent experiments and each was performed in triplicate. ${ }^{*} \mathrm{P}<0.05$ and ${ }^{* *} \mathrm{P}<0.01$ vs. A549 cells. HNK, honokiol; CUR, curcumin; DDP, cisplatin; OD, optical density.

and the optimal concentrations of HNK, CUR and DDP were selected for further studies. A549 and A549/DDP cells were treated with increasing concentrations of $\operatorname{HNK}(0,5,10,20,40$ and $80 \mu \mathrm{g} / \mathrm{ml}), \operatorname{CUR}(0,5,10,20,40$ and $80 \mu \mathrm{g} / \mathrm{ml})$ and DDP $(0,5,10,20,40$ and $80 \mu \mathrm{g} / \mathrm{ml})$ for $48 \mathrm{~h}$. From the results of Fig. 1A-C, A549 cells were more sensitive to HNK, CUR and DDP with increasing concentrations than A549/DDP cells, in accordance with previous studies $(15,20)$. It was found that HNK $(5 \mu \mathrm{g} / \mathrm{ml})$, CUR $(10 \mu \mathrm{g} / \mathrm{ml})$ and DDP $(5 \mu \mathrm{g} / \mathrm{ml})$ displayed no significant cytotoxicity in A549/DDP cells compared with that in A549 cells. Therefore, HNK $(5 \mu \mathrm{g} / \mathrm{ml})$, CUR $(10 \mu \mathrm{g} / \mathrm{ml})$ and DDP $(5 \mu \mathrm{g} / \mathrm{ml})$ were chosen as the optimal concentrations for further experimentation.

Effects of HNK orland CUR on activity and proliferation of A549 cells and A549/DDP cells. The activity and proliferation of A549 cells and A549/DDP cells was respectively detected by MTS assay and colony-forming assay. Compared with the control group, all groups could inhibit cell activity in A549 (Fig. 2A). However, as shown in Fig. 2B, compared with the control group, the cell activity of HNK, CUR, DDP and HNK + CUR groups was not significantly changed in A549/DDP cells. In contrast, the cell activity in HNK + DDP and CUR + DDP groups was significantly suppressed. Meanwhile, the cell activity rate of $\mathrm{HNK}+\mathrm{CUR}+\mathrm{DDP}$ group was significantly depressed compared with that of $\mathrm{HNK}+\mathrm{DDP}$ or CUR + DDP groups. The results of cell proliferation were consistent with MTS assay (Fig. 2C). The data revealed that HNK or/and CUR could reverse resistance to DDP in A549/DDP cells.

Effects of HNK orland CUR on apoptosis of A549/DDP cells by flow cytometry assay. The results of Fig. 3 indicated that after treatment with HNK, CUR, DDP and HNK + CUR, the cell apoptosis rate was as same as that in the control group. While A549/DDP cells were treated with HNK + DDP and CUR + DDP, the apoptosis rate of A549/DDP cells was obviously enhanced. Further, compared with HNK + DDP or CUR + DDP groups, the cell apoptosis rate of HNK + Cur + DDP group was significantly upregulated.

Effects of HNK orland CUR on migration of A549/DDP cells by wound healing assay. Following wound healing assay, the results of Fig. 4 suggested that there was no difference between the control group and HNK, CUR, DDP and HNK + CUR groups. In addition, the wound healing rates were significantly depressed with HNK + DDP and CUR + DDP treatment in 24 and 48 h compared with wound healing rate of the control group. The results identified that the wound healing rate of HNK + CUR + DDP group was significantly downregulated compared with that of HNK + DDP or CUR + DDP groups in 24 and $48 \mathrm{~h}$, respectively.

Effects of HNK or/and CUR on invasion of A549/DDP cells by Transwell assay. The data from Fig. 5 demonstrated that the invading cell numbers of HNK, CUR, DDP and HNK + CUR groups were the same as the control group. After treatment with HNK + DDP and CUR + DDP, the invading cell numbers were significantly suppressed compared with the control group. Compared with HNK + DDP or Cur + DDP groups, the invading cell numbers of the HNK + CUR + DDP group was significantly decreased.

Effects of HNK orland CUR on P-gp protein nuclear volume of A549/DDP cells by immunofluorescence assay. Following immunofluorescence, the results of Fig. 6 
A

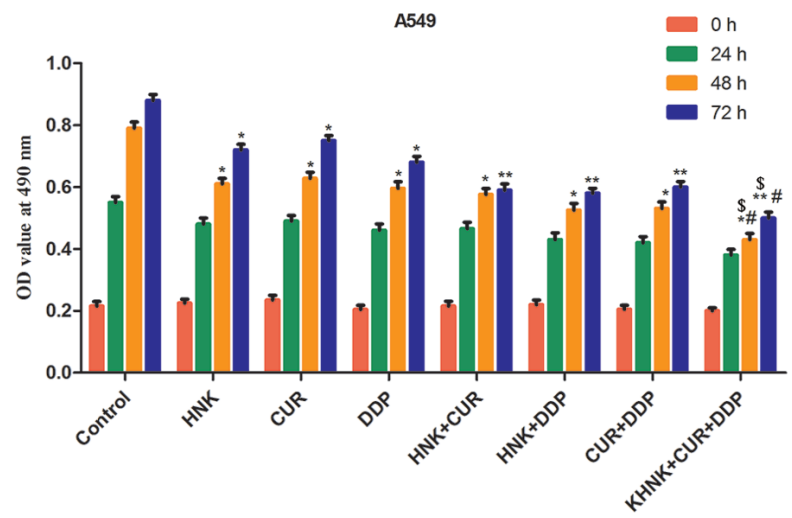

C

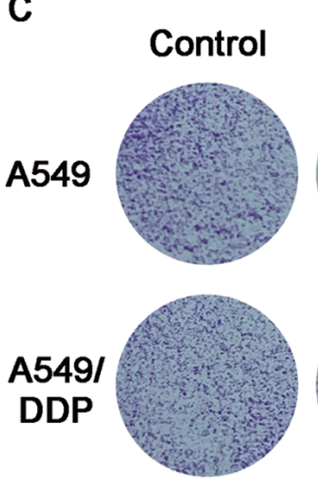

D
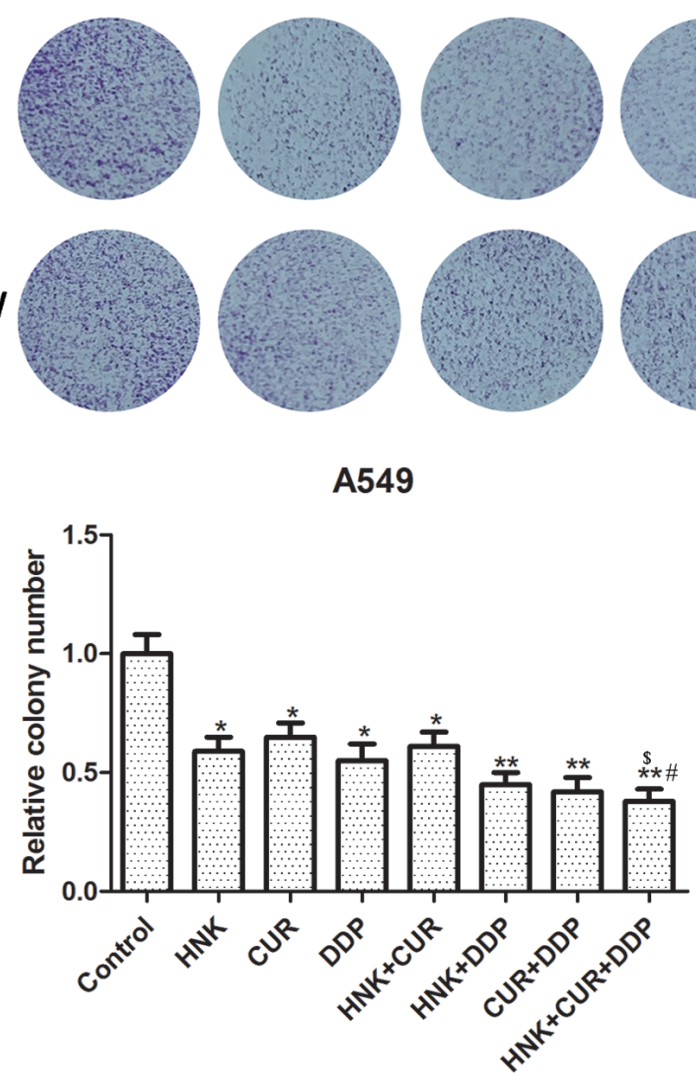

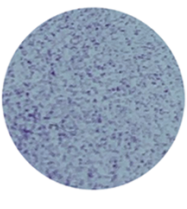

A549
B

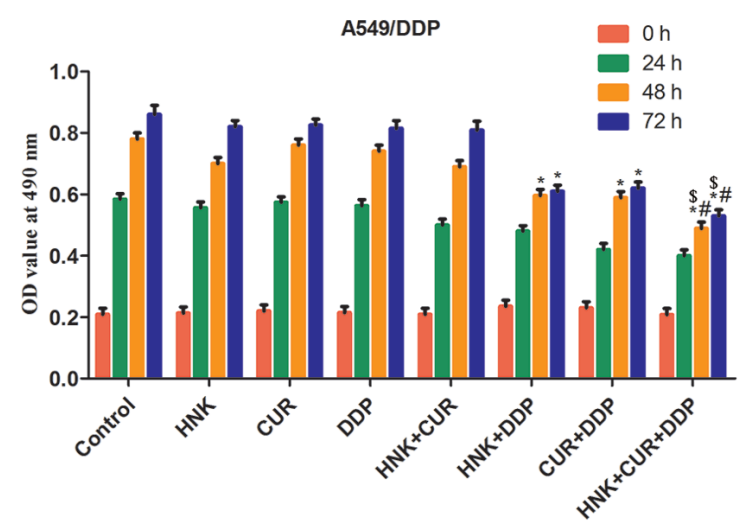

\section{HNK+}

HNK+ DDP

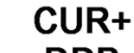

HNK+CUR CUR
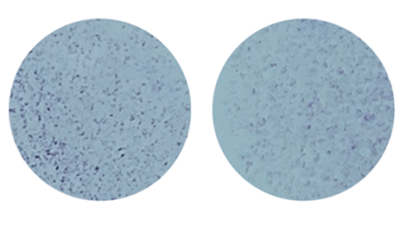
+DDP
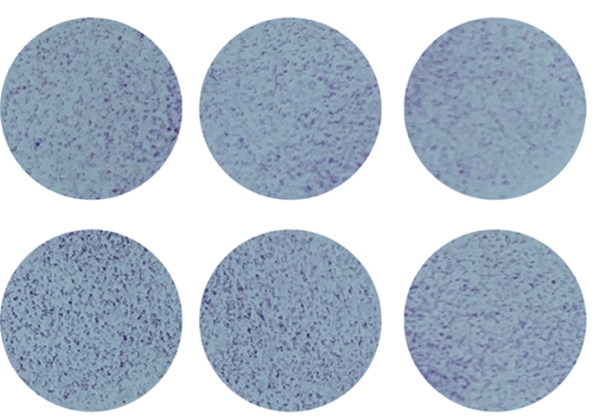

E
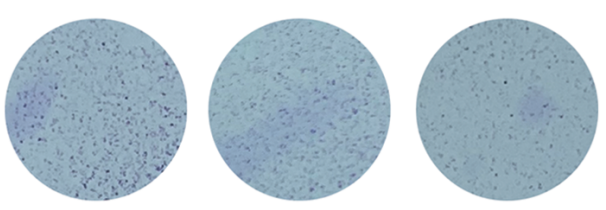

A549/DDP

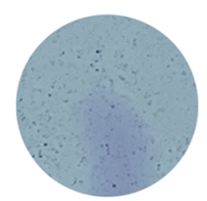

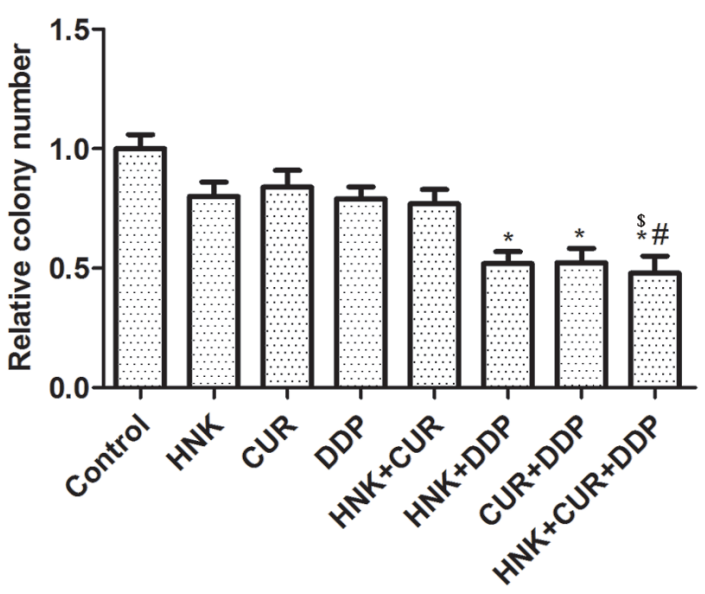

Figure 2. Effects of HNK or/and CUR on activity and proliferation of A549/DDP cells. The activity of (A) A549 and (B) A549/DDP cells administered HNK, CUR, DDP, HNK + CUR, HNK + DDP, CUR + DDP and HNK + CUR + DDP were examined by MTS assay. ${ }^{*}<0.05$ and ${ }^{* *} \mathrm{P}<0.01$ vs. Control group, ${ }^{\#} \mathrm{P}<0.05$ vs. HNK + DDP group, ${ }^{\$} \mathrm{P}<0.05$ vs. CUR + DDP group. (C) The proliferation of A549 and A549/DDP cells administered with HNK, CUR, DDP, HNK + CUR, HNK + DDP, CUR + DDP and HNK + CUR + DDP were examined by colony formation assay. Quantification of (D) A549 and (E) A549/DDP cell colony formation. Magnification, $x 40$. The results were expressed as the mean \pm standard deviation of three independent experiments and each was performed in triplicate. ${ }^{*} \mathrm{P}<0.05$ and ${ }^{* *} \mathrm{P}<0.01$ vs. control group, ${ }^{\sharp} \mathrm{P}<0.05$ vs. HNK + DDP group, ${ }^{\$} \mathrm{P}<0.05$ vs. CUR + DDP group. HNK, honokiol; CUR, curcumin; DDP, cisplatin; OD, optical density.

demonstrated that the P-gp nuclear volume of HNK, CUR, DDP and HNK + CUR groups was similar to that of the control group. In addition, the P-gp nuclear volume of HNK + DDP and CUR + DDP groups were significantly inhibited compared with the control group, and the P-gp nuclear volume of HNK + CUR + DDP group was significantly downregulated compared with that of HNK + DDP or CUR + DDP groups.
Effects of HNK orland CUR on the mRNA expression of the AKT/Erk signaling pathway by RT-qPCR assay. As demonstrated in Fig. 7, the mRNA expression of P-gp, p21, MMP-2, MMP-9, AKT, Erk1/2, caspase-3, caspase-9 and PARP in HNK, CUR, DDP and HNK + CUR groups was not obviously upregulated or downregulated compared with the control group. Conversely, the P-gp, MMP-2, MMP-9, AKT and Erk1/2 mRNA expression of HNK + DDP and 
A

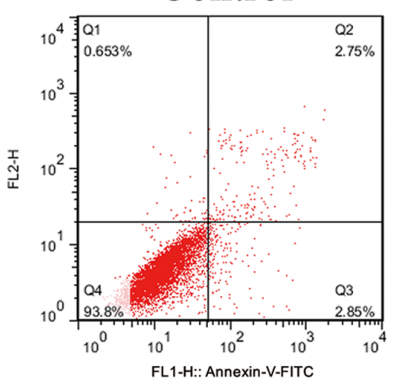

$\mathrm{HNK}+\mathrm{CUR}$

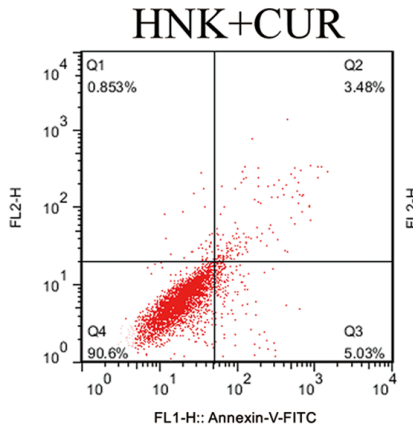

HNK

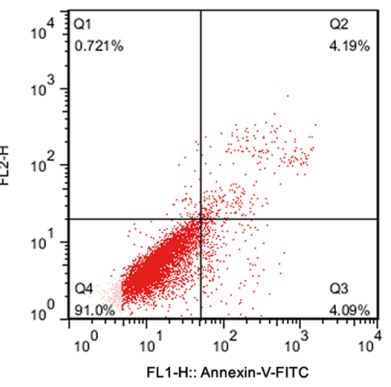

$\mathrm{HNK}+\mathrm{DDP}$

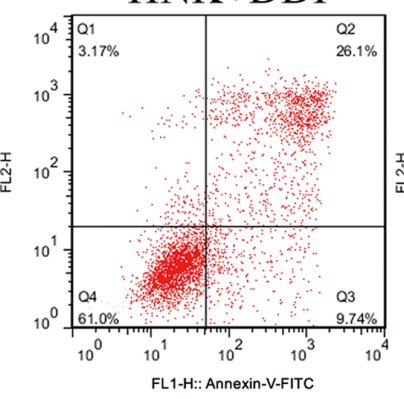

CUR
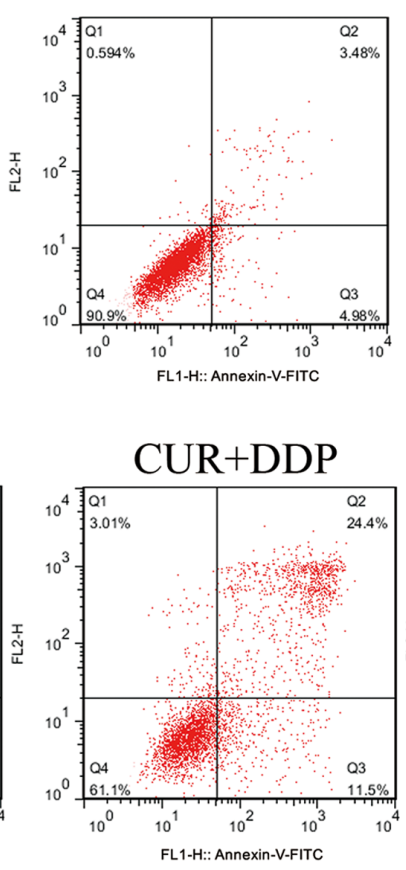

DDP

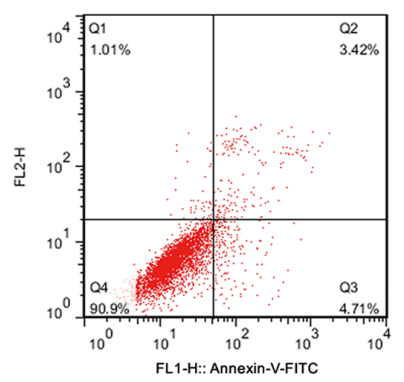

$\mathrm{HNK}+\mathrm{CUR}$

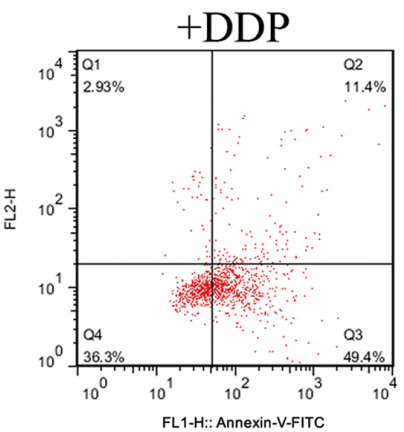

B

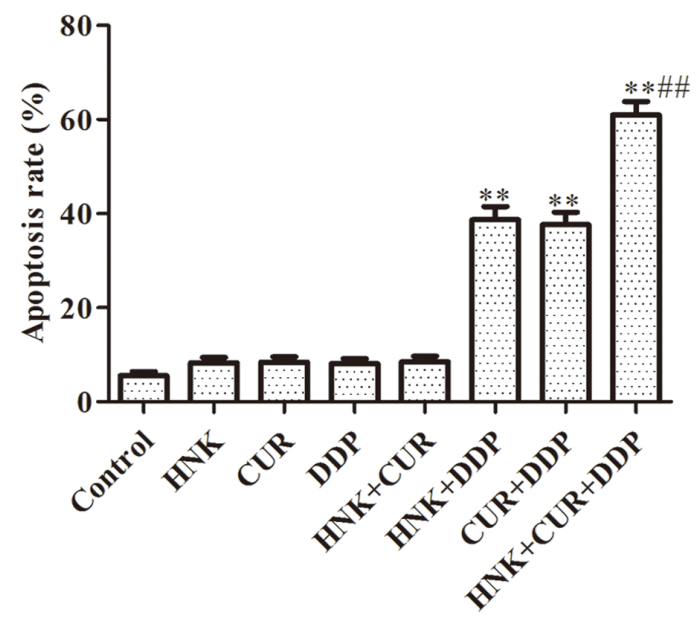

Figure 3. Effects of HNK or/and CUR on apoptosis of A549/DDP cells by flow cytometry. (A) A549/DDP cells treated with HNK, CUR, DDP, HNK + CUR, HNK + DDP, CUR + DDP and HNK + CUR + DDP for 48 h were harvested for flow cytometry analysis. (B) Annexin V/PI-stained cells were analyzed with the percentages of apoptosis cells. ${ }^{* *} \mathrm{P}<0.01$ vs. control group, ${ }^{\# \#} \mathrm{P}<0.01$ vs. HNK + DDP group or CUR + DDP group. HNK, honokiol; CUR, curcumin; DDP, cisplatin.

CUR + DDP groups was significantly downregulated and the p21, caspase-3, caspase-9 and PARP mRNA expression of the HNK + DDP and CUR + DDP groups was significantly upregulated compared with those of control group. The effects of $\mathrm{HNK}+\mathrm{CUR}+\mathrm{DDP}$ on the mRNA expression of P-gp, MMP-2, MMP-9, AKT and Erk1/2 was increased compared than those of HNK + DDP or CUR + DDP groups. P21, caspase-3, caspase-9 and PARP mRNA expression were enhanced in HNK + CUR + DDP group.

Effects of HNK orland CUR on the protein levels of AKT/Erk signal pathway by western blot assay. The results of Fig. 8 demonstrated that there was no significant difference in protein expression of P-gp, p21, MMP-2, MMP-9,
p-AKT, AKT, p-Erk1/2, ERK, caspase-3, cleaved-caspase-3, caspase-9, cleaved caspase-9, PARP and cleaved PARP between the control group and HNK, CUR, DDP and HNK + CUR groups. Following treatment with HNK + DDP, the protein levels of P-gp, MMP-2, MMP-9, p-AKT and p-Erk1/2 were respectively decreased by 54, 26, 38, 28 and $33 \%$, and the protein expression of p21, cleaved-caspase-3, cleaved caspase-9 and cleaved PARP was respectively increased by 35, 21, 29 and $23 \%$, compared with the control. Following treatment with CUR + DDP, the protein expression of P-gp, MMP-2, MMP-9, p-AKT and p-Erk1/2 was respectively decreased by 58,30,36, 27 and $34 \%$, and the protein expression of p21, cleaved-caspase-3, cleaved caspase- 9 and cleaved PARP was respectively increased by $39,20,31$ and 

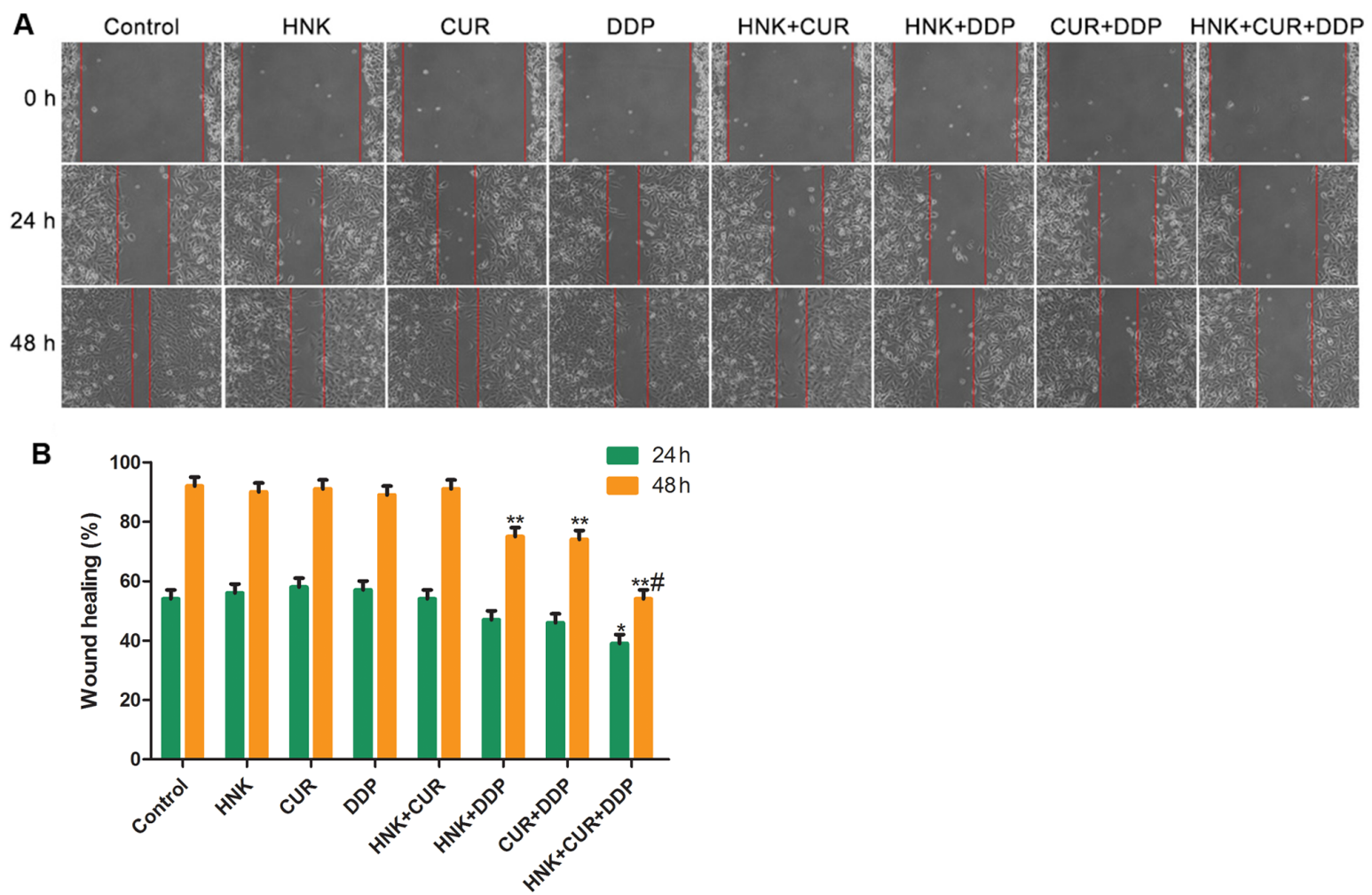

Figure 4. Effects of HNK or/and CUR on migration of A549/DDP cells by wound healing assay. (A) The migration abilities of A549/DDP cells treated with HNK, CUR, DDP, HNK + CUR, HNK + DDP, CUR + DDP and HNK + CUR + DDP for 24 or 48 h were examined by wound healing assay. Magnification, $\mathrm{x} 200$. (B) Wound healing percentage are shown in chart. ${ }^{*} \mathrm{P}<0.05$ and ${ }^{* *} \mathrm{P}<0.01$ vs. control group, ${ }^{\text {}} \mathrm{P}<0.05$ vs. HNK $+\mathrm{DDP}$ group or CUR $+\mathrm{DDP}$ group. HNK, honokiol; CUR, curcumin; DDP, cisplatin.
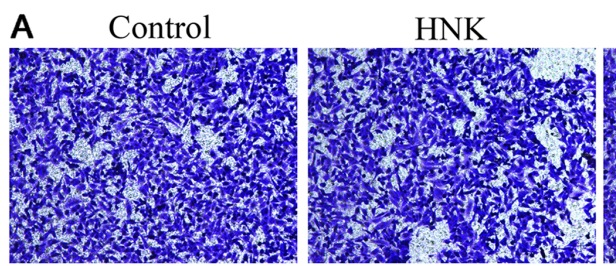

CUR

DDP

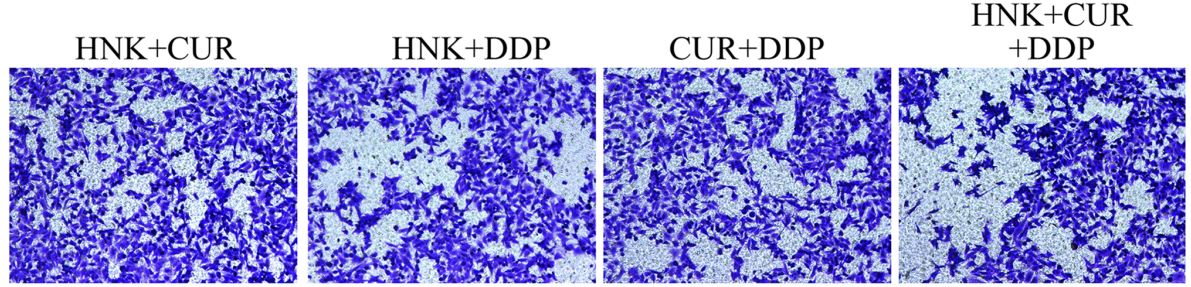

B

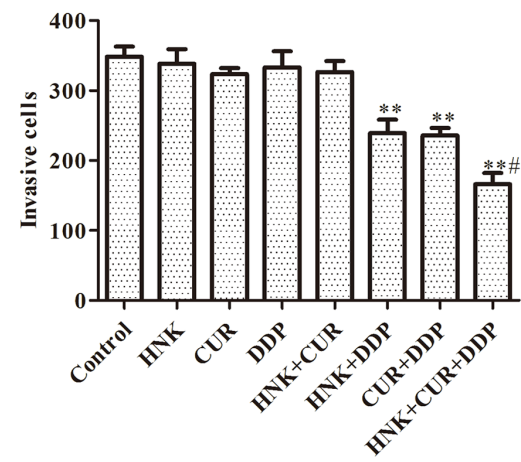

Figure 5. Effects of HNK or/and CUR on invasion of A549/DDP cells by Transwell assay. (A) The invasion abilities of A549/DDP cells treated with HNK, CUR, DDP, HNK + CUR, HNK + DDP, CUR + DDP and HNK + CUR + DDP for $48 \mathrm{~h}$ were evaluated Transwell invasion assay and (B) analyzed. Magnification, $\mathrm{x} 200$. The results were expressed as the mean \pm standard deviation of three independent experiments and each was performed in triplicate. ${ }^{* *} \mathrm{P}<0.01$ vs. control group, ${ }^{\#} \mathrm{P}<0.05$ vs. HNK + DDP group or CUR + DDP group. HNK, honokiol; CUR, curcumin; DDP, cisplatin. 

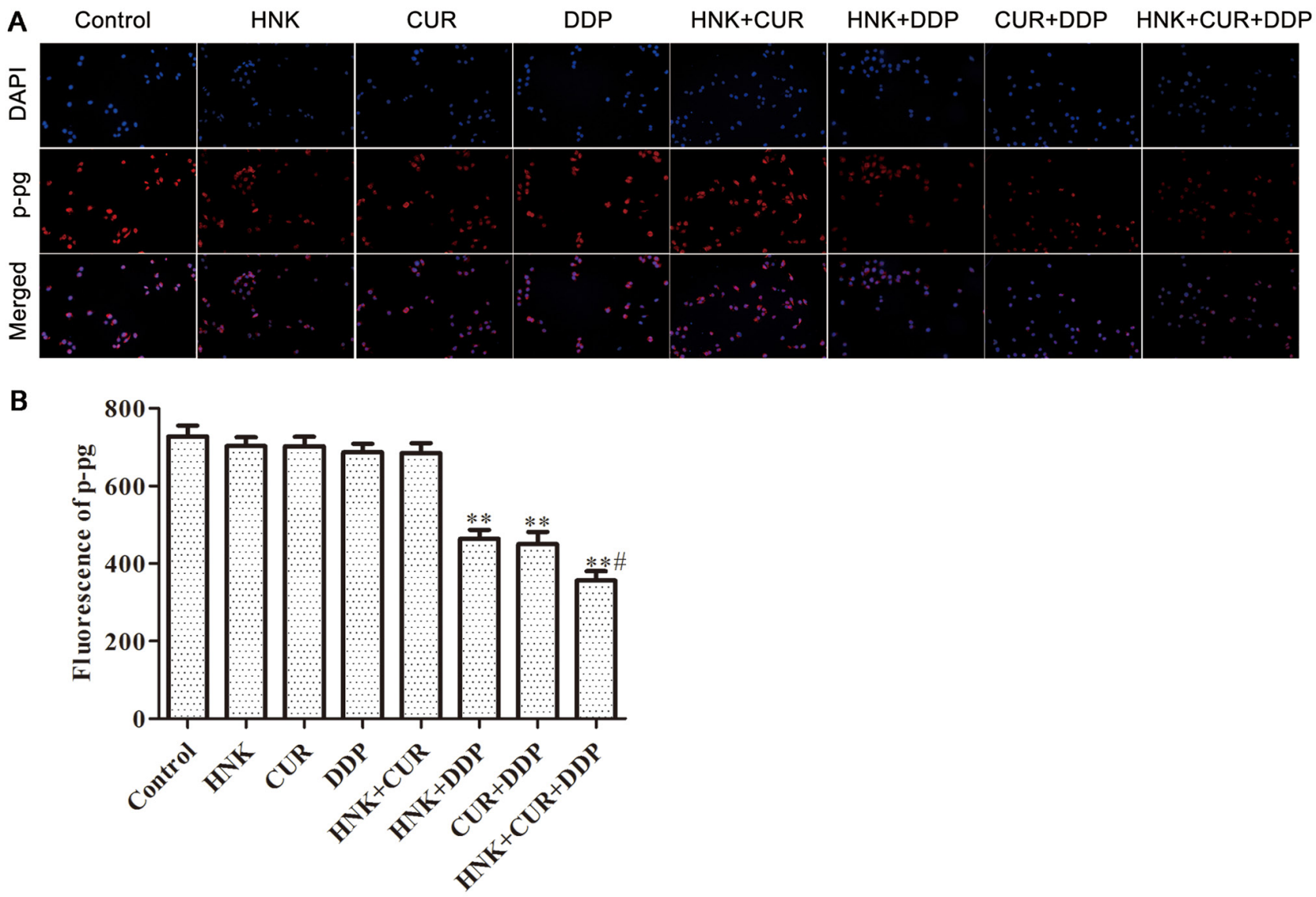

Figure 6. Effects of HNK or/and CUR on P-gp protein nuclear volume of A549/DDP cells by immunofluorescence assay. (A) The P-gp protein nuclear volume of A549/DDP cells treated with HNK, CUR, DDP, HNK + CUR, HNK + DDP, CUR + DDP and HNK + CUR + DDP for $48 \mathrm{~h}$ were determined by immunofluorescence assay and (B) analyzed. Magnification, $\mathrm{x} 200 .{ }^{* *} \mathrm{P}<0.01$ vs. control group, ${ }^{~} \mathrm{P}<0.05$ vs. HNK + DDP group or CUR + DDP group. HNK, honokiol; CUR, curcumin; P-gp, P-glycoprotein; DDP, cisplatin.

$26 \%$, compared with the control. Following treatment with $\mathrm{HNK}+\mathrm{CUR}+\mathrm{DDP}$, the protein expression of P-gp, MMP-2, MMP-9, p-AKT and p-Erk1/2 was respectively decreased by $65,45,51,40$ and $50 \%$, and the protein expression of $\mathrm{p} 21$, cleaved-caspase-3, cleaved caspase- 9 and cleaved PARP was respectively increased by $58,34,47$ and $48 \%$, compared with the control.

\section{Discussion}

HNK is a natural compound that not only shows antibacterial, anti-inflammatory and anti-anxiety effects, but also promotes the apoptosis of tumor cells (21). Relevant studies have confirmed that HNK can reverse drug resistance of both solid tumors (such as breast cancer) and hematopoietic tumors (such as myeloma) (22-24). Li et al (25) found that HNK inhibited the expression of ZEB2 by upregulating microRNA-141, thereby reducing the stemness of renal cancer cells. Treatment of oral cancer stem cells with magnolol induced stem cell apoptosis and inhibited the $\mathrm{Wnt} / \beta$-catenin signaling pathway, which is also important for stemness maintenance (26). In colon cancer cells, HNK significantly inhibited activity of the Notch signaling pathway (27). HNK can also damage glioma stem cells and reverse drug-resistance of glioma cells (28). CUR is a phenolic pigment extracted from Curcuma longa, a plant of the ginger family. CUR shows strong effects to induce apoptosis of tumor cells and to inhibit tumor cell proliferation and invasion (29). Previous studies have demonstrated that CUR can also effectively reverse MDR of multiple types of tumors (30-32). Almanaa et al (33) found that CUR treatment not only kills normal esophageal cancer cells, but also kills esophageal cancer stem cells. CUR can induce apoptosis of colorectal cancer stem cells by binding to CD44 antigen on the surface of colorectal cancer stem cells (34). The E-cadherin/ $\beta$-catenin negative feedback signal in breast cancer cells can be amplified by CUR, which leads to the obstruction of tumor stem cell migration (35). The results of the present study indicated that HNK or CUR reversed drug resistance of A549/DDP cells to DDP alone and combination of HNK and CUR demonstrated stronger drug resistance reversal effects.

P-gp binds to the chemotherapeutic drug molecules after they enter the tumor cells and pumps the drugs out of the cell using energy derived from ATP hydrolysis, thus reducing intracellular drug concentration, hence overexpression of P-gp causes resistance to the drug (36). The results of the present study demonstrated that HNK or CUR combined with DDP reduced P-gp expression and reduced nuclear import of P-gp, which are considered an important part in reversing drug resistance of A549/DDP cells. HNK and CUR combined with DDP had a stronger inhibitory effect on P-gp expression. 
A

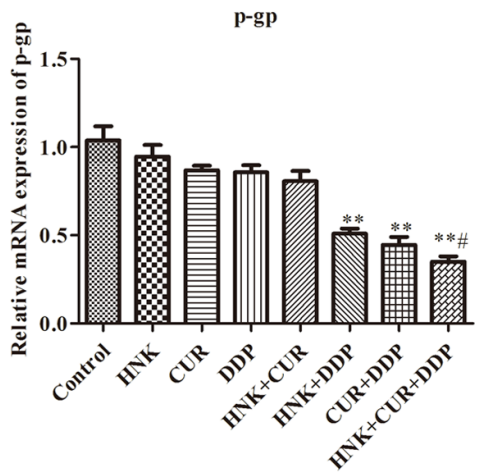

D

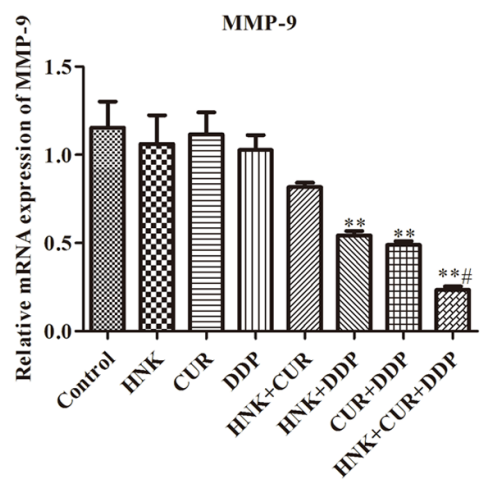

G

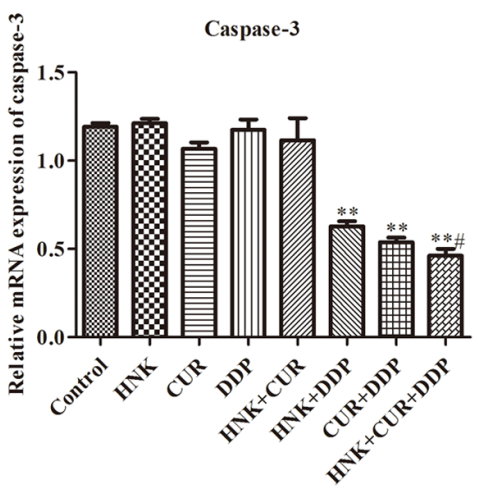

B

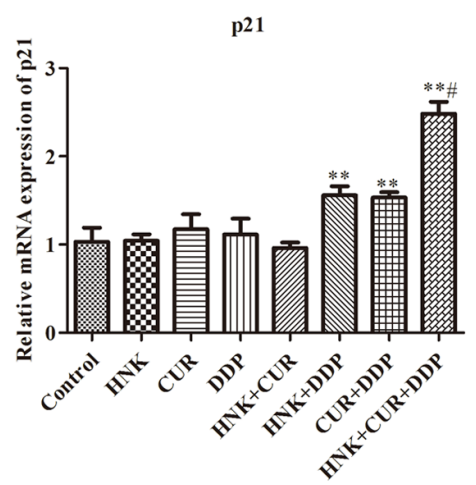

E

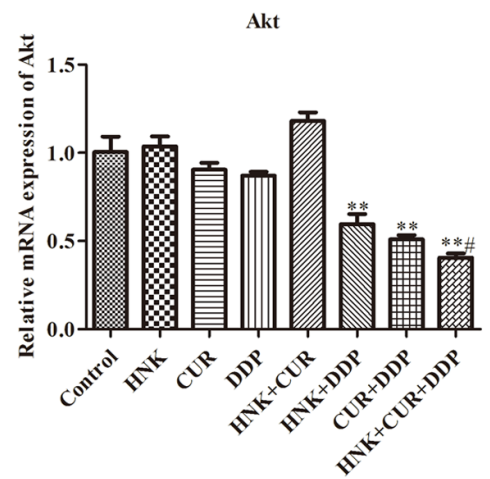

H

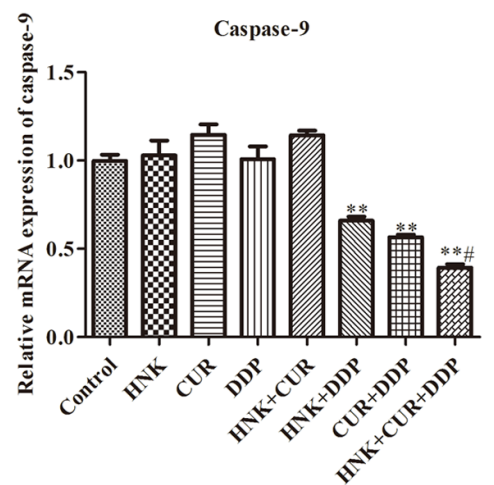

C

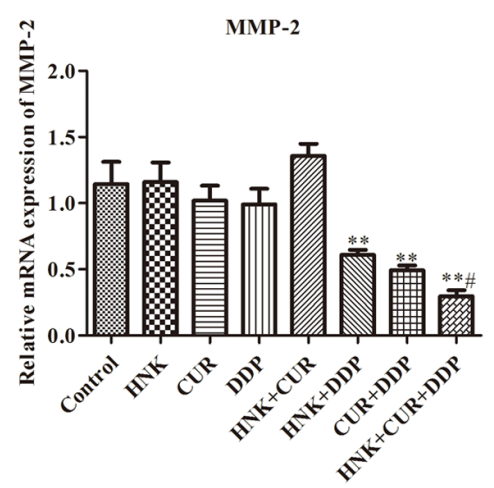

F

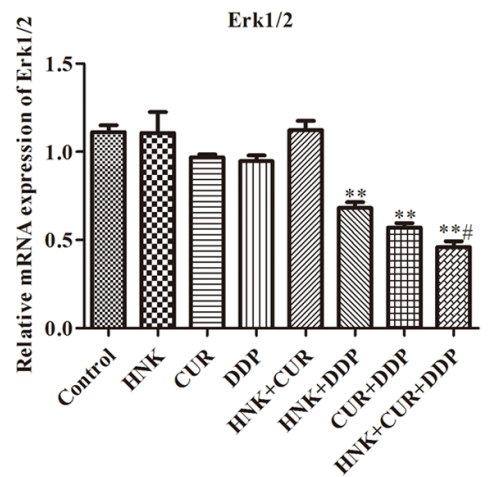

I

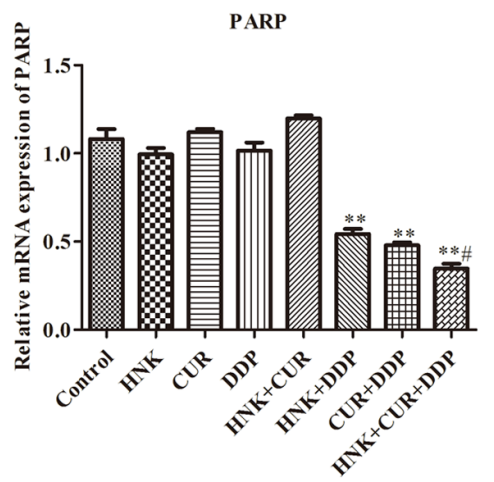

Figure 7. Effects of HNK or/and CUR on the related mRNA expressions of AKT/Erk signal pathway by RT-qPCR. The mRNA expression of (A) P-gp, (B) P21, (C) MMP-2, (D) MMP-9, (E) Akt, (F) Erk1/2, (G) caspase-3, (H) caspase-9, (I) and PARP in A549/DDP cells treated with HNK, CUR, DDP, HNK + CUR, HNK + DDP, CUR + DDP and HNK + CUR + DDP for $48 \mathrm{~h}$ were evaluated by RT-qPCR assay. The results were expressed as the mean \pm standard deviation of three independent experiments and each was performed in triplicate. ${ }^{* *} \mathrm{P}<0.01$ vs. control group, ${ }^{\text {"P }}<0.05$ vs. HNK $+\mathrm{DDP}$ group or CUR $+\mathrm{DDP}$ group. HNK, honokiol; CUR, curcumin; RT-qPCR, reverse transcription-quantitative PCR; P-gp, P-glycoprotein; MMP, matrix metalloproteinase; PARP, poly ADP-ribose polymerase; DDP, cisplatin; p, phosphorylated.

Activation of the AKT/ERK signaling pathway is closely related to enhanced tumor activity and reducing P-gp expression has been shown to effectively inhibit occurrence and progression of tumors (37-39). In the present study, HNK or CUR combined with DDP decreased activation of $\mathrm{p}-\mathrm{AKT}$ and p-ERK1/2 compared with the control in A549/DDP cells, and the effect of HNK and CRU was more evident. Caspase-3 and caspase-9 are the key proteases concerned with cell apoptosis. Activated caspase- 3 and caspase- 9 can be split into cleaved caspase- 3 and cleaved caspase- 9 , and then hydrolyze cell structural proteins to promote the disintegration of apoptotic cells. Furthermore, PARP is split into cleaved-PARP, which ultimately leads to apoptosis. Cleavage levels of caspase-3, caspase-9 and PARP can reflect the level of apoptosis $(40,41)$. The present study demonstrated that the ratios of cleaved caspase-3/caspase-3, cleaved caspase-9/caspase- 9 and cleaved PARP/PARP were increased following activation of AKT/ERK signal pathway in A549/DDP cells. The results revealed that HNK or CRU combined with DDP inhibited cell proliferation, induced apoptosis and increased the ratios of cleaved caspase-3/caspase-3, cleaved caspase-9/caspase-9 and cleaved PARP/PARP in A549/DDP cells, and the effect of HNK and CRU was clear. A previous study found that p21 is also involved in the migration and invasion of cancer cells (42). MMP-2/9 has been shown to be involved in tumor invasion and migration (43). MMPs are the main rate-limiting 
A

C

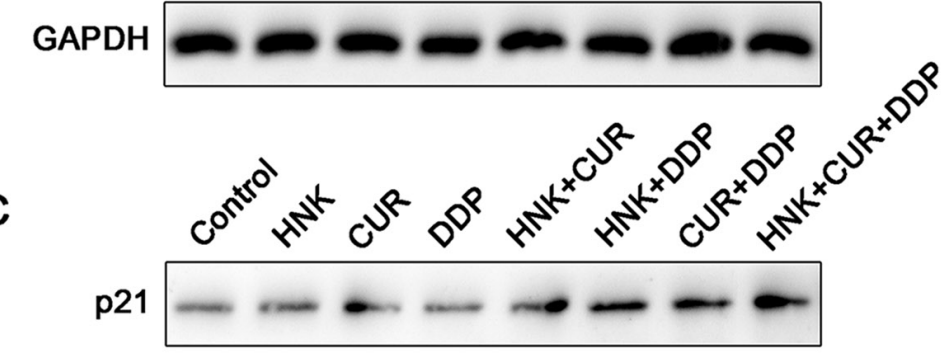

MMP-2

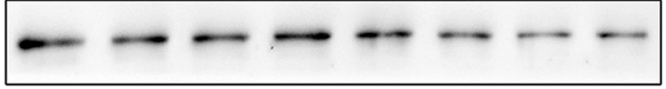

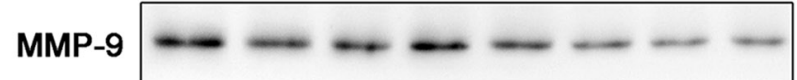

GAPDH

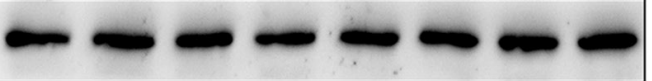

E

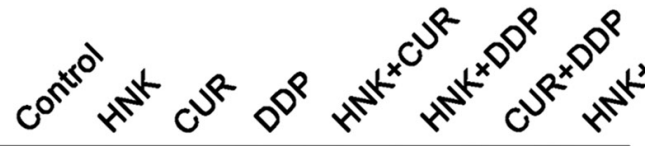

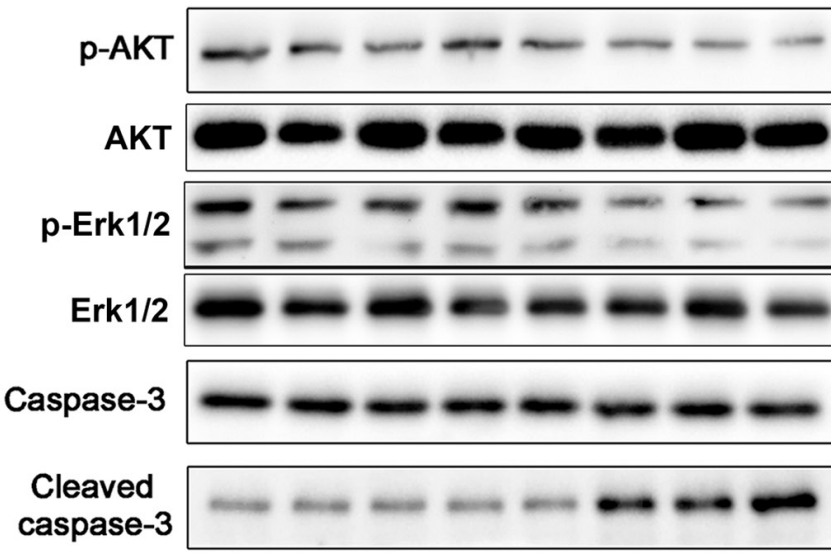

Caspase-9

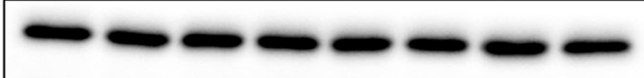

Cleaved caspase-9

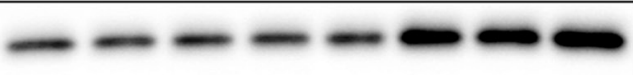

\section{PARP}
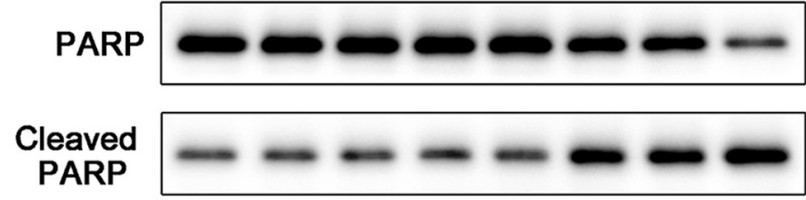

GAPDH

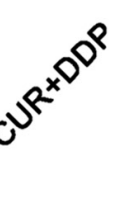

$\mathbf{F}$

D

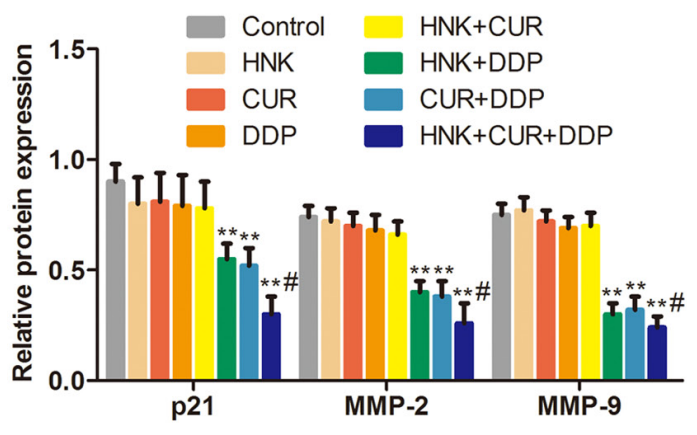

$\mathbf{B}$
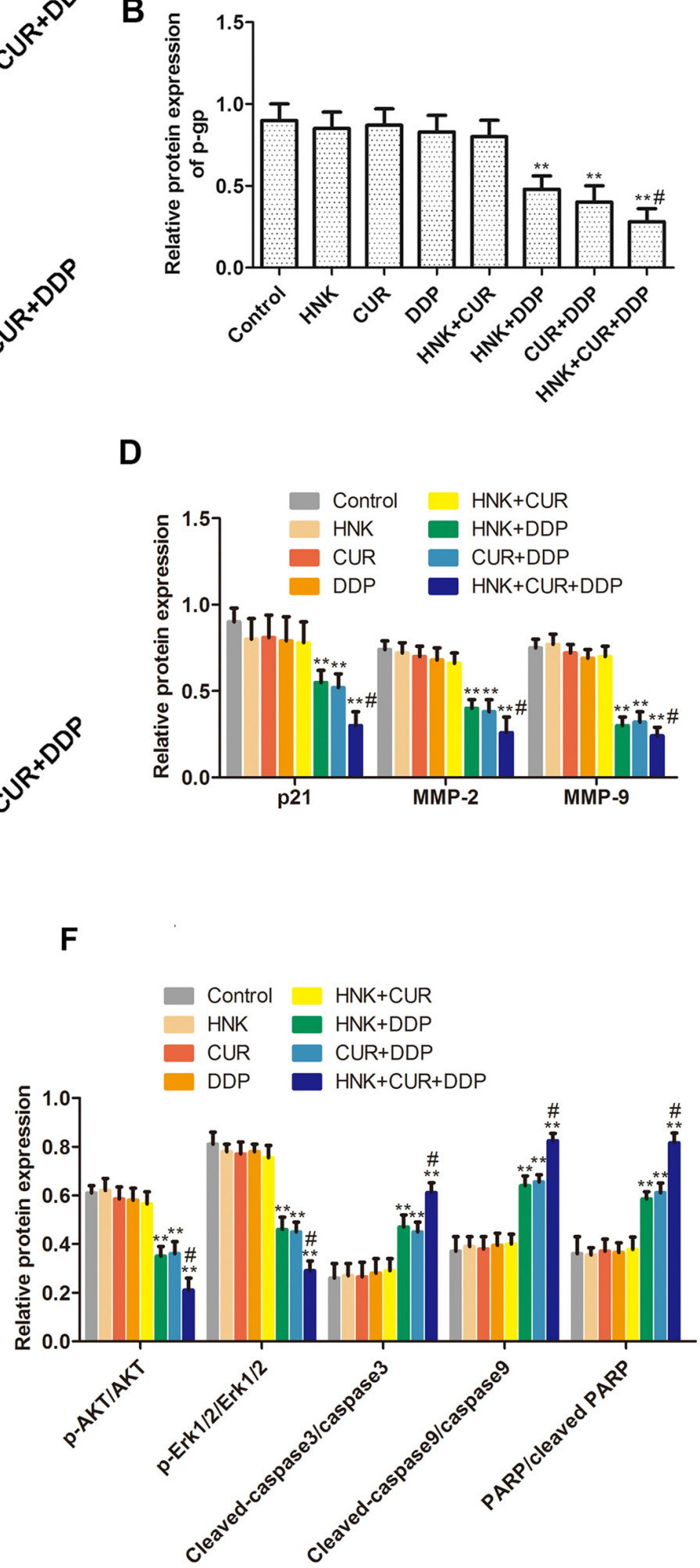

Figure 8. Effects of HNK or/and CUR on the related protein expression of the AKT/Erk signal pathway by western blot assay. (A) The protein expression of P-gp and (B) analysis. (C) The protein expression of P21, MMP-2 and MMP-9 and (D) analysis of in A549/DDP cells treated with HNK, CUR, DDP, HNK + CUR, HNK + DDP, CUR + DDP and HNK + CUR + DDP for $48 \mathrm{~h}$ were evaluated by western blot assay. (E) Protein levels of p-AKT, AKT, p-Erk1/2, Erk1/2, caspase-3, cleaved caspase-3, caspase-9, cleaved caspase-9, PARP and cleaved PARP and (F) densitometry analysis. The band intensity was quantified by ImageJ software. ${ }^{* *} \mathrm{P}<0.01$ vs. control group, ${ }^{*} \mathrm{P}<0.05$ vs. HNK + DDP group or CUR + DDP group. HNK, honokiol; CUR, curcumin; MMP, matrix metalloproteinase; DDP, cisplatin. 
enzymes regulating the metabolism of the extracellular matrix and are named for their ability to degrade extracellular matrix and their need for metal ions such as $\mathrm{Ca}^{2+}$ and $\mathrm{Zn}^{2+}$ as cofactors (44). MMP-2 and MMP-9 can degrade gelatin, laminin and type IV collagen, and play an important role in invasion and metastasis of various malignant tumors $(45,46)$. The results of the present study demonstrated that HNK or/and CUR inhibited invasion and metastasis of A549/DDP cells, and decreased the expression of p21, MMP-2 and MMP-9. These effects could reverse the resistance of A549/DDP cells to DDP by increasing P-gp expression, by inhibiting cell proliferation and promoting apoptosis, and by inhibiting cell migration and invasion.

HNK and CUR are extracts in traditional Chinese medicine, which possess low toxicity, and have been shown to have antitumor effects. Although the reversal effect of the two drugs is weak when they are used alone, the effect is enhanced when they are used together. The present study demonstrated that the combination of the two low-toxicity drugs with synergistic effect can significantly enhance the reversal effect. This provides a strong theoretical and experimental basis for the clinical application of new drugs to reverse tumor MDR. In summary, the results of the present study demonstrated that HNK and CUR could reverse drug resistance of lung cancer cells and the two in combination demonstrated synergistic effects and could significantly reverse the drug resistance of lung cancer cell lines. The present study described the inhibitory effects of HNK or/ and CUR on lung cancer resistance in vitro, but not in vivo. Moreover, some of the images are of poor quality.

\section{Acknowledgements}

Not applicable.

\section{Funding}

This present study was supported by the National Natural Science Foundation of Jiangsu Higher Education Institutions (grant no. 17KJB360008).

\section{Availability of data and materials}

The datasets used and/or analyzed during the current study are available from the corresponding author on reasonable request.

\section{Authors' contributions}

MQ designed the experiments. XC and LB were the major contributors to the interpretation of data for the work. $\mathrm{HZ}$ and JM performed the experiments. All authors read and approved the final version of the manuscript.

\section{Ethics approval and consent to participate}

Not applicable.

\section{Patient consent for publication}

Not applicable.

\section{Competing interests}

The authors declare that they have no competing interests.

\section{References}

1. Zheng R, Zeng H, Zhang S, Fan Y, Qiao Y, Zhou Q and Chen W: Lung cancer incidence and mortality in China, 2010. Thorac Cancer 5: 330-336, 2014.

2. She J, Yang P, Hong Q and Bai C: Lung cancer in China: Challenges and interventions. Chest 143: 1117-1126, 2013.

3. Schwartz AM and Rezaei MK: Diagnostic surgical pathology in lung cancer: Diagnosis and management of lung cancer, 3rd ed: American College of Chest Physicians evidence-based clinical practice guidelines. Chest 143 (Suppl 5): Se251-Se262, 2013.

4. Collins LG, Haines C, Perkel R and Enck RE: Lung cancer: Diagnosis and management. Am Fam Physician 75: 56-63, 2007.

5. Goldstraw P, Ball D, Jett JR, Le Chevalier T, Lim E, Nicholson AG and Shepherd FA: Non-small-cell lung cancer. Lancet 378: 1727-1740, 2011.

6. Fennell DA, Summers Y, Cadranel J, Benepal T, Christoph DC, Lal R, Das M, Maxwell F, Visseren-Grul C and Ferry D: Cisplatin in the modern era: The backbone of first-line chemotherapy for non-small cell lung cancer. Cancer Treat Rev 44: 42-50, 2016.

7. Amable L: Cisplatin resistance and opportunities for precision medicine. Pharmacol Res 106: 27-36, 2016.

8. Holford J, Sharp SY, Murrer BA, Abrams M and Kelland LR: In vitro circumvention of cisplatin resistance by the novel sterically hindered platinum complex AMD473. Br J Cancer 77: 366-373, 1998.

9. Averett C, Arora S, Zubair H, Singh S, Bhardwaj A and Singh AP: Molecular targets of Honokiol: A promising phytochemical for effective cancer management. Enzymes 36: 175-193, 2014.

10. Park E, Min H, Chung H, Hong J, Kang Y, Hung T, Youn U, Kim Y, Bae K, Kang S and Lee S: Down-regulation of c-Src/EGFR-mediated signaling activation is involved in the honokiol-induced cell cycle arrest and apoptosis in MDA-MB-231 human breast cancer cells. Cancer Lett 277: 133-140, 2009.

11. Fan Y, Xue W, Schachner M and Zhao W: Honokiol eliminates glioma/glioblastoma stem cell-like cells via JAK-STAT3 signaling and inhibits tumor progression by targeting epidermal growth factor receptor. Cancers (Basel) 11: 22, 2018.

12. Sengupta S, Nagalingam A, Muniraj N, Bonner MY, Mistriotis P, Afthinos A, Kuppusamy P, Lanoue D, Cho S, Korangath P, et al: Activation of tumor suppressor LKB1 by honokiol abrogates cancer stem-like phenotype in breast cancer via inhibition of oncogenic Stat3. Oncogene 36: 5709-5721, 2017.

13. Wu H, Yin Z, Wang L, Li F and Qiu Y: Honokiol improved chondrogenesis and suppressed inflammation in human umbilical cord derived mesenchymal stem cells via blocking nuclear factor- $\kappa$ B pathway. BMC Cell Biol 18: 29, 2017.

14. Li Y and Zhang T: Targeting cancer stem cells by curcumin and clinical applications. Cancer Lett 346: 197-205, 2014.

15. Cheng Q, Liao M, Hu H, Li H and Wu L: Asiatic acid (AA) sensitizes multidrug-resistant human lung adenocarcinoma A549/DDP cells to cisplatin (DDP) via downregulation of P-Glycoprotein (MDR1) and its targets. Cell Physiol Biochem 47: 279-292, 2018.

16. Chen LP, Wang P, Sun YJ and Wu YJ: Direct interaction of avermectin with epidermal growth factor receptor mediates the penetration resistance in Drosophila larvae. Open Biol 6: 150231, 2016.

17. Liu Z, Sun M, Lu K, Liu J, Zhang M, Wu W, De W, Wang Z and Wang R: The long noncoding RNA HOTAIR contributes to cisplatin resistance of human lung adenocarcinoma cells via downregualtion of p21WAF1/CIP1 expression. PLoS One 8: e77293-e77303, 2013.

18. Lin Y, Duan Q and Yang YP: Immunohistochemistry of phosphatase and tensin homolog and metalloproteinase-9 in breast invasive micropapillary carcinoma. Eur J Gynaecol Oncol 40: 380-383, 2019.

19. Livak KJ and Schmittgen TD: Analysis of relative gene expression data using real-time quantitative PCR and the 2(-Delta Delta C(T)) method. Methods 25: 402-408, 2001.

20. Dong Z, Ren L, Lin L, Li J, Huang Y and Li J: Effect of microRNA-21 on multidrug resistance reversal in A549/DDP human lung cancer cells. Mol Med Rep 11: 682-690, 2014. 
21. Xu D, Lu Q and Hu X: Down-regulation of P-glycoprotein expression in MDR breast cancer cell MCF-7/ADR by honokiol. Cancer Lett 243: 274-280, 2006.

22. Ishitsuka K, Hideshima T, Hamasaki M, Raje N, Kumar S, Hideshima H, Shiraishi N, Yasui H, Roccaro AM, Richardson $\mathrm{P}$, et al: Honokiol overcomes conventional drug resistance in human multiple myeloma by induction of caspase-dependent and -independent apoptosis. Blood 106: 1794-1800, 2005.

23. Lee S, Khoo C, Halstead CW, Huynh T and Bensoussan A: Liquid chromatographic determination of honokiol and magnolol in hou po (Magnolia officinalis) as the raw herb and dried aqueous extract. J AOAC Int 90: 1210-1218, 2019.

24. Chio CC, Chen KY, Chang CK, Chuang JY, Liu CC, Liu SH and Chen RM: Improved effects of honokiol on temozolomide-induced autophagy and apoptosis of drug-sensitive and -tolerant glioma cells. BMC Cancer 18: 379, 2018.

25. Li W, Wang Q, Su Q, Ma D, An C, Ma L and Liang H: Honokiol suppresses renal cancer cells' metastasis via dual-blocking epithelial-mesenchymal transition and cancer stem cell properties through modulating miR-141/ZEB2 signaling. Mol Cells 37: 383-388, 2014

26. Yao C, Lai G, Yeh C, Lai M, Shih P, Chao W, Whang-Peng J, Chuang S and Lai T: Honokiol eliminates human oral cancer stem-like cells accompanied with suppression of Wnt/ $\beta$-catenin signaling and apoptosis induction. Evid Based Complement Alternat Med 2013: 146136, 2013.

27. Wynn M, Consul N, Merajver S and Schnell S: Inferring the effects of honokiol on the notch signaling pathway in SW480 colon cancer cells. Cancer Inform 13 (Suppl 5): S1-S12, 2014.

28. Lai I, Shih P, Yao C, Yeh C, Wang-Peng J, Lui T, Chuang S, Hu T, Lai T and Lai G: Elimination of cancer stem-like cells and potentiation of temozolomide sensitivity by Honokiol in glioblastoma multiforme cells. PLoS One 10: e0114830, 2015.

29. Ye M, Zhang J, Zhang J, Miao Q, Yao L and Zhang J: Curcumin promotes apoptosis by activating the p53-miR-1922-5p/215-XIAP pathway in non-small cell lung cancer. Cancer Lett 357: 196-205, 2015.

30. Lv L, Qiu K, Yu X, Chen C, Qin F, Shi Y, Ou J, Zhang T, Zhu H, Wu J, et al: Amphiphilic copolymeric micelles for doxorubicin and curcumin co-delivery to reverse multidrug resistance in breast cancer. J Biomed Nanotechnol 12: 973-985, 2016.

31. Yuan HB, Meng PY and Qi LJ: Curcumin up-regulates miR-133a expression to inhibit hepatocellular carcinoma cell migration and invasion. World Chinese J Digestol, 2019.

32. Hosseini A, Rasmi Y, Rahbarghazi R, Aramwit P, Daeihassani B and Saboory E: Curcumin modulates the angiogenic potential of human endothelial cells via FAK/P-38 MAPK signaling pathway. Gene 688: 7-12, 2019.

33. Almanaa T, Geusz $M$ and Jamasbi R: Effects of curcumin on stem-like cells in human esophageal squamous carcinoma cell lines. BMC Complement Altern Med 12: 195, 2012.
34. Huang Y, Lin Y, Chiu $\mathrm{H}$ and Chiang B: Curcumin induces apoptosis of colorectal cancer stem cells by coupling with CD44 marker. J Agric Food Chem 64: 2247-2253, 2016.

35. Mukherjee S, Mazumdar M, Chakraborty S, Manna A, Saha S, Khan P, Bhattacharjee P, Guha D, Adhikary A, Mukhjerjee S and Das T: Curcumin inhibits breast cancer stem cell migration by amplifying the E-cadherin/ $\beta$-catenin negative feedback loop. Stem Cell Res Ther 5: 116, 2014.

36. Wilkens S: Structure and mechanism of ABC transporters. F1000Prime Rep 7: 14, 2015.

37. Liu CH, Huang Q, Jin ZY, Zhu CL, Liu Z and Wang C: miR-21 and KLF4 jointly augment epithelial-mesenchymal transition via the Akt/ERK1/2 pathway. Int J Oncol 50: 1109-1115, 2017.

38. Zhang S, Bian H, Li X, Wu H, Bi Q, Yan Y and Wang Y: Hydrogen sulfide promotes cell proliferation of oral cancer through activation of the COX2/AKT/ERK1/2 axis. Oncol Rep 35: 2825-2832, 2016.

39. Krebs K, Ruusmann A, Simonlatser $G$ and Velling $T$ : Expression of FLNa in human melanoma cells regulates the function of integrin $\alpha 1 \beta 1$ and phosphorylation and localisation of PKB/AKT/ERK1/2 kinases. Eur J Cell Biol 94: 564-575, 2015.

40. Hu Y, Hong Y, Xu Y, Liu P, Guo DH and Chen Y: Inhibition of the JAK/STAT pathway with ruxolitinib overcomes cisplatin resistance in non-small-cell lung cancer NSCLC. Apoptosis 19: 1627-1636, 2014.

41. Zhang W, Zhou H, Yu Y, Li J, Li H, Jiang D, Chen Z, Yang D, $\mathrm{Xu} \mathrm{Z}$ and $\mathrm{Yu} \mathrm{Z}$ : Combination of gambogic acid with cisplatin enhances the antitumor effects on cisplatin-resistant lung cancer cells by downregulating MRP2 and LRP expression. Onco Targets Ther 9: 3359-3368, 2016.

42. Dai M, Alodaini AA, Filsaimé N, Villatoro MA, Guo J, Arakelian A, Rabbani SA, Ali S and Lebrun JJ: Cyclin D1 cooperates with p21 to regulate TGF $\beta$-mediated breast cancer cell migration and tumor local invasion. Breast Cancer Res 15: 3246, 2013

43. Giganti Mg, Tresoldi I, Sorge R, Melchiorri G, Triossi T, Masuelli L, Lido P, Albonici L, Foti C, Modesti A and Bei R: Physical exercise modulates the level of serum MMP-2 and MMP-9 in patients with breast cancer. Oncol Lett 12: 2119-2126, 2016.

44. Jayakumar T, Liu CH, Wu GY, Lee TY, Manubolu M, Hsieh CY, Yang $\mathrm{CH}$ and Sheu JR: Hinokitiol inhibits migration of A549 lung cancer cells via Suppression of MMPs and induction of antioxidant enzymes and apoptosis. Int J Mol Sci 19: 939, 2018.

45. Laskowska M: Altered maternal serum matrix metalloproteinases MMP-2, MMP-3, MMP-9, and MMP-13 in severe early- and late-onset preeclampsia. Biomed Res Int 2017: 6432426, 2017.

46. Chen J, Ren Z, Zhu M and Khalil RA: Decreased homodimerization and increased TIMP-1 complexation of uteroplacental and uterine arterial matrix metalloproteinase- 9 during hypertension-in-pregnancy. Biochem Pharmacol 138: 81-95, 2017. 